\section{P68 LEAN - LOOKING WITH FRESH EYES}

Susan Bridger, Debbie Collins, Rebecca Loan, Jacqui Tomsett. Farleigh Hospice, Chelmsford, United Kingdom

\subsection{6/bmjspcare-2013-000591.90}

Introduction The hospice has continually strived to provide the most efficient and streamlined services possible, right across the organisation. In August 2011 in was decided to introduce 'Lean'. organisational improvement principles. 4 staff from different departments were trained as Lean Advisers to embed the principles of Lean within all areas of the hospice.

This is the journey of the introduction and development of 'Lean' to support organisational improvement.

Aim

- To demonstrate the development of the role of the 'LEAN' Advisers to empower and support staff in their review of departmental processes using 'LEAN' principles and techniques.

- To discuss process and outcomes of projects undertaken in clinical care, fundraising, staff support and environmental efficiency

- To discuss lessons learnt

- To discuss where we go from here

Methods

- Developed a timeline to plot the journey to introduce Lean Principles.

- Ongoing training provided on a voluntary basis by a Lean consultant

- Use of a variety of Lean tools to collect and analyse data

Results To date two projects have been completed - 1 reviewing and streamlining of the patients journey through the hospice which has resulted in cost savings on staffing and an increase in patient contacts by community staff. 2 the running and management of OT \& Physio equipment stores which has resulted in a more efficient and safer service to patients. 3 other projects are in progress.

Conclusion

- It is far too easy to offer solutions to a problem before understanding what is really going on

- It is far too easy to implement a process/solution for a problem and then think the job is done

- A group of people from different backgrounds with LEAN training can make a massive difference to a service

\section{P69 RECRUITING OUR WORKFORCE USING VALUE BASED INTERVIEWING}

Rachel Power. Richard House Children's Hospice, Beckton, United Kingdom

\subsection{6/bmjspcare-2013-000591.91}

National research and enquires have highlighted a gap between the espouced values within care environments and the quality of care people receive. Richard House recognises the relationship between high quality care and the values and attitudes of staff and volunteers.

Richard House implemented value based interviewing (VBI) as part of our recruitment process in 2012 to seek to ensure that the values of Richard House are reflected in the day to day care and support it provides to children, young people and their families.
Core values were drawn up by the staff and volunteers who also helped develop the positive and negative indicators.

Value Based Interviewing is underpinned by robust research and it has been proven this interviewing method facilitates the recruitment of people more aligned with organisational values and behaviours and helps recruit high performing and effective staff and volunteers.

VBI has been used and established in a number of organisations including the NSPCC. It has been shown to effectively identify candidates who are a "better fit" for Richard House and therefore the right people to support the service for children young people and their families.

\section{P70 DEVELOPING AND CELEBRATING GOOD PRACTICE IN A HOSPICE SETTING: EQUIPPING A WORKFORCE FOR A CHANGING AND UNCERTAIN FUTURE}

Sue Griffith, Kate Powis. St Helena Hospice, Colchester, UK

\subsection{6/bmjspcare-2013-000591.92}

Background In the current climate of austerity and need to demonstrate that hospices are able to prepare for a changing future of widening access, it is important that hospices take every opportunity to develop practice and ensure the whole workforce is abreast of current thinking. Furthermore, this development must be made explicit to staff and all stakeholders. Having always prided itself on being a centre of excellence, this hospice sought to demonstrate this by being recognised as a practice development unit.

Approach After working with a university to reach first stage accreditation, it was acknowledged that the framework to achieve this was too rigid and costly for a charitable organisation. The existing education and research group was amalgamated with the practice development team to create a Hospice Education And Research and Development (HEARD) group to ensure that every aspect of hospice care follows a practice development approach.

Outcomes The group HEARD offers everyone in the organisation a voice, and a place for their development ideas to be heard. It meets bi-monthly to examine current practice, ideas for research and publication, and to plan a series of learning events to meet changing educational needs of all hospice staff. This plans to generate evidence, develop practice, disseminate good practice, and share best evidence through a journal club, with a focus on developing the workforce and leadership abilities through a largely bottom-up approach.

Application To preserve the academic rigour of the practice development process, eight criteria were created to guide innovation, and the group has a steering committee. Two successful celebration days have now been held to showcase practice developments to stakeholders and staff. An electronic source of educational information has developed from this; the research behind which, as well as other developments, have been published and shared at international conferences.

\section{P71 INTERGRATING A NEW HOSPICE PAY POLICY WITH A NURSING COMPETENCY FRAMEWORK}

Ruth Bacon, Tara Schrikker, Karen Clarke. St Wilfrids Hospice, Eastbourne, UK

10.1136/bmjspcare-2013-000591.93 
Introduction The hospice decided to formulate a new nursing pay structure which moved away from Agenda for Change principles and integrated an updated competency framework. Aims

- Create a pay policy to reflect local market conditions and respond to hospice needs whilst being flexible

- Develop a "balanced" nursing skill mix which reflects the hospice's needs

- Establish core requirements for each nursing post

- Link competence with pay

- Develop a pay and competence framework in consultation with staff.

Method Using best practice documents, the hospice reviewed and updated existing competencies before implementation.

Registered Nurses engaged with the new process by:-

- Attending teaching sessions on

- Introduction to Competencies: How, What, Why and When!

- Getting Started with your Competencies

- Meeting with Line Managers on a 1:1 basis

A structure consisting of Foundation, Intermediary and Tenure levels of competency and pay was introduced.

Results The implementation of a competence related pay structure appears to have had a positive effect on staff engagement and motivation. Improved awareness, communication, education and support have resulted.

Staff feel more confident working at the competency level which reflects their experiences and skills.

Conclusion Having the competencies linked into Performance Development Review process enables a cycle of reflection, support, training and evaluation.

The framework encourages and supports staff to work to their potential to provide specialist palliative care and respond to organisational needs.

\section{\begin{tabular}{|l|l}
\hline P72 LEAVING HOME - MANAGING CHANGE \\
\hline
\end{tabular}}

Karen Clarke. St Wilfrid's Hospice, Eastbourne, UK

\subsection{6/bmjspcare-2013-000591.94}

Background Autumn 2013 the hospice will relocate to its new 20-bedded facility. To have a successful move staff/volunteers need to feel supported and engaged.

Aim Change Management Strategy was implemented to:

- generate interest, energy and enthusiasm

- empower managers to take ownership and problem solve

- engage employees, patients and their families

- implement the practical steps to ensure safe working practices

- attract and retain new employees and volunteers whilst ensuring low turnover.

Approach Staff Engagement questionnaire (September 2011) assessed staffs' preparedness for change.

1. Change management programme developed based upon Kotter, Lewin and Kübler-Ross.

2. Communication - briefings; hospice newsletter; team meetings; 1:1's; Away Days.

3. Patients Forum worked with the Deputy CEO on all aspects of the new hospice since June 2011.
4. September 2012 - Day Therapy patient group focused on the new Wellbeing Centre.

5. Staff/volunteers involvement:
a. site visits
b. Farewell Project
c. furniture and equipment consultation
d. piloting proposed changes
e. planning decant strategy
f. charting hospice's history
g. developing operational plans
h. developing orientation/induction programme.

\section{Outcomes}

- 77 volunteers have confirmed they will relocate

- $<10$ staff indicated they will not be relocating

- Site visit feedback:

- "gives a feeling of being involved in the change process literally from 'the ground up",

- "incredibly inspiring ... really helped to bring the vision to life....will help immensely when having discussions with staff, patients and relatives about the new hospice."

- Further outcomes available post move.

Application At a time of unprecedented change in the hospice movement it is important not to lose sight of the impact on staff and volunteers:

"One of the greatest costs of change is that impact on the ability of staff to respect and care for others while they feel under threat themselves.” (Iles 2005).

\section{P73 DOES THE ATTACHMENT STYLE OF HOSPICE WORKERS PREDICT THEIR EMOTIONAL RESPONSE TO A MOVE INTO A BESPOKE NEW BUILD UNIT?}

Chantal Meystre, Jane Murray, Kathy Armour. Marie Curie Hospice, West Midlands, Solihull, UK

10.1136/bmjspcare-2013-000591.95

Aim To investigate the relationship between psychological attachment style and emotional responses to moving into a purpose built hospice.

Background Mental representations of self and other are formed by our primary relationship. Internal working models inform subsequent relationships, world view and responses to life events. Attachment style research demonstrates predictive value for staff responses in clinical environments. In 2013 our hospice service relocated to a bespoke new build. Practical issues were addressed by project management, but psychological and emotional aspects were unexplored.

Methodology After favourable University ethics review the study took place in an English, 17 bedded consultant-led hospice with daycare, and community services. All staff and visiting volunteers were eligible for the study. A modified adult attachment questionnaire with added elements was circulated prior to moving. Gender was not collected to ensure confidentiality.

Results 42 questionnaires (31\%) were returned: 34 staff, 8 volunteers. Statistical analysis revealed no difference between staff and volunteers so they are reported together. The median length of service at the old Hospice was 6.2 years; range $<1$ to 23 years service. Older staff had worked for the hospice for longer $(\mathrm{p}<0.05)$.

Anxious and avoidant attachment styles were not related to length of service in the hospice. Staff with anxious attachment 